\title{
Thermometry Issues in Destruction Kinetics Measurement
}

\author{
June 9, 2009 \\ Dean Ripple \\ dean.ripple@nist.gov \\ NIST Thermometry Group
}

Overview of thermometer types, terminology, \& general issues

Detailed discussion of different thermometer types

Verification \& good practice 


\section{Effects of Temperature on Microbes}

\section{Small temperature changes:}

Arrhenius Equation: reaction rate constant proportional to $e^{-E_{a} / R T}$ ( $E_{a}=$ activation energy, $R=$ gas constant, $T=$ absolute temperature) Modification of protein enzymatic kinetics

Even small changes in temperature, at relatively low temperature, can lead to significant changes in rate of microbial inactivation

Large temperature changes:

Activation of protective pathways (e.g., heat-shock proteins)

Physical alterations to proteins, DNA

Accurate thermometry aids in determination of damage thresholds

Accurate measurements ensure validity and interchangeability of kinetics data, for both thermal and thermally assisted inactivation 


\section{Tolerances vs. Calibration Uncertainties}

Tolerance band: manufacturer's guarantee that the instrument response will conform to a standard response function to within an error equal to the tolerance.

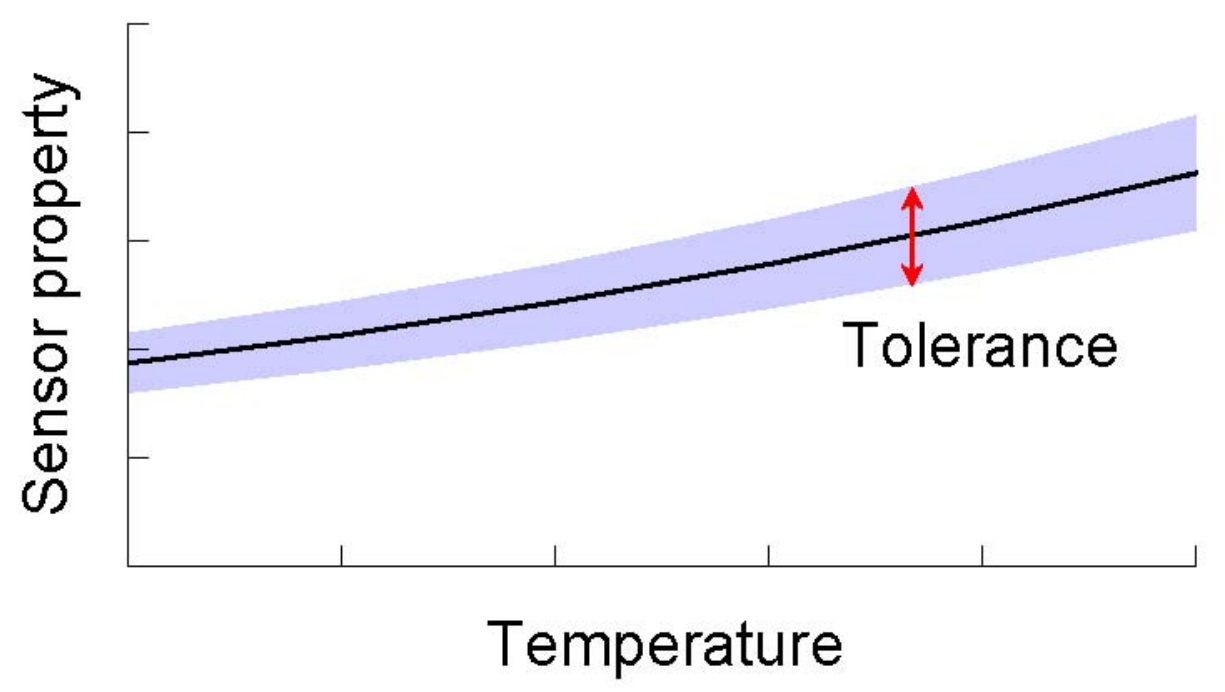

Calibrated thermometer: may or may not have a response close to the nominal response function for that thermometer type.

Response of individual unit is reported. Expanded uncertainties (95\% confidence limit, or 'coverage factor $k=2$ ') typically reported for calibration measurement-not including drift \& user readout

Individually calibrated thermometers are not interchangeable, unless the readouts or software are adjusted. 


\section{Typical Measurement Uncertainty Budget}

\section{Component}

Calibration uncertainty or tolerance

Sensor drift

Readout uncertainty

Temperature stability

Temperature non-uniformity

\section{Method of evaluation}

Manufacturer, calibration report, or tolerance

Literature, manufacturer, recalibration, or in situ check

Manufacturer or independent evaluation

Logging of temperature

Move probe or use multiple probes

Note that only the first item is included in the initial calibration or manufacturing tolerance 


\section{Thermometer Types}

Standard Platinum Resistance Thermometers (SPRTs)

$\$ 6000$

(very accurate, but susceptible to shock)

$-259{ }^{\circ} \mathrm{C}$ to $962{ }^{\circ} \mathrm{C}$

Industrial Platinum Resistance Thermometers (IPRTs) $\mathbf{\$ 2 0 0}$ to $\mathbf{\$ 2 0 0 0}$ $-196{ }^{\circ} \mathrm{C}$ to $850^{\circ} \mathrm{C}$

Thermistors

$\$ 200$ to $\$ 2000$

$-50{ }^{\circ} \mathrm{C}$ to $100^{\circ} \mathrm{C}$

Thermocouples $\$ 100$ to $\$ 1000$

$-196^{\circ} \mathrm{C}$ to $2100^{\circ} \mathrm{C}$

Liquid-in-Glass Thermometers

$\$ 20$ to $\$ 400$

$-150{ }^{\circ} \mathrm{C}$ to $400{ }^{\circ} \mathrm{C}$

Digital Thermometers (PRT, thermistor, or thermocouple in disguise) $-196{ }^{\circ} \mathrm{C}$ to $850^{\circ} \mathrm{C}$ 


\section{Approximate Measurement Uncertainties of Complete Systems}

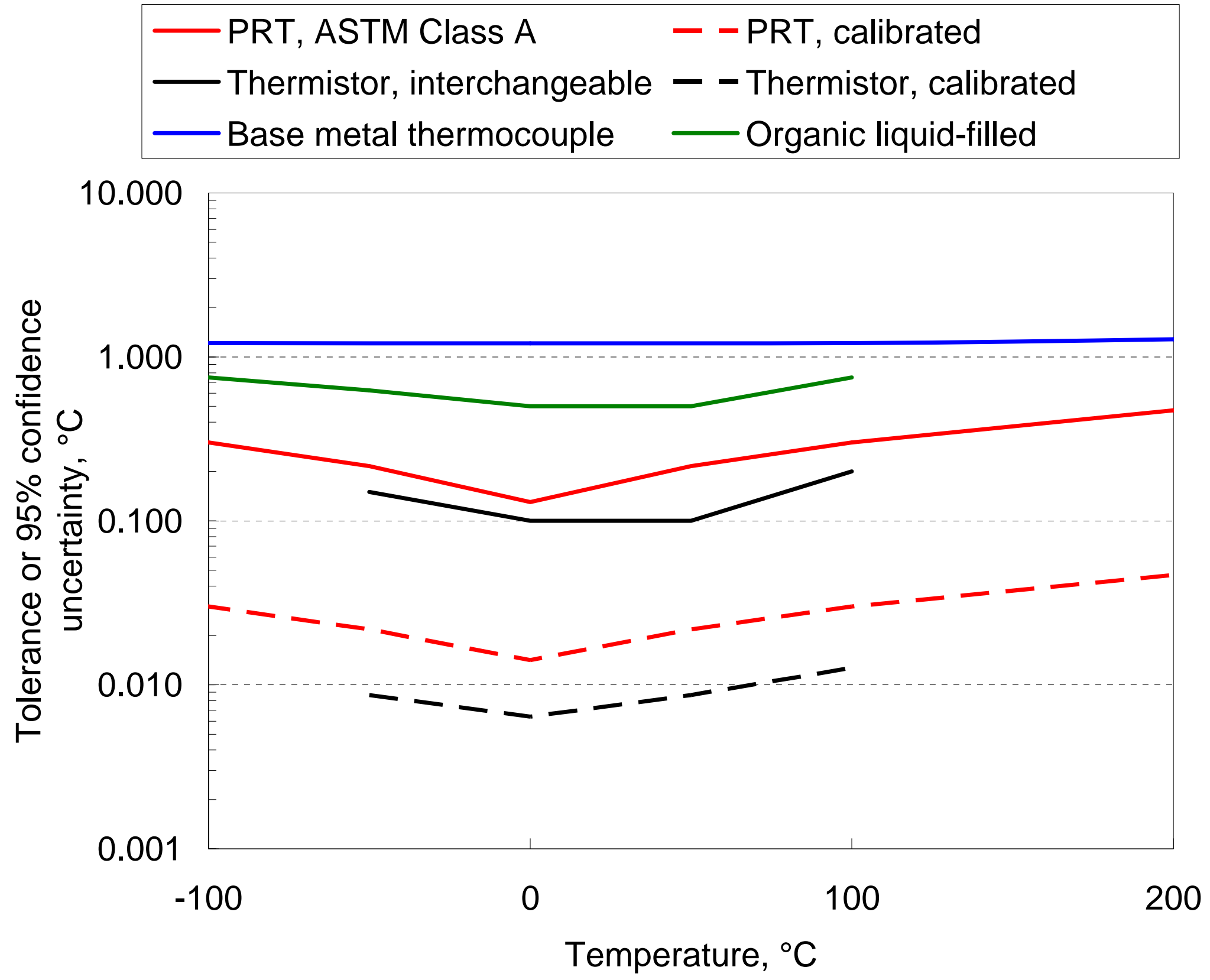




\section{Types of Liquid-in-Glass (LiG) Thermometers}

Types of ASTM LiG thermometers

- Over 120 types

- Total Immersion: immerse thermometer nearly up to top of capillary

- Partial Immersion: immerse a designated, fixed depth (e.g., 76 mm)

Liquids used

- Mercury $(\mathrm{Hg})$ - ASTM (sales regulated)

- Organic

- Proprietary (non-toxic)

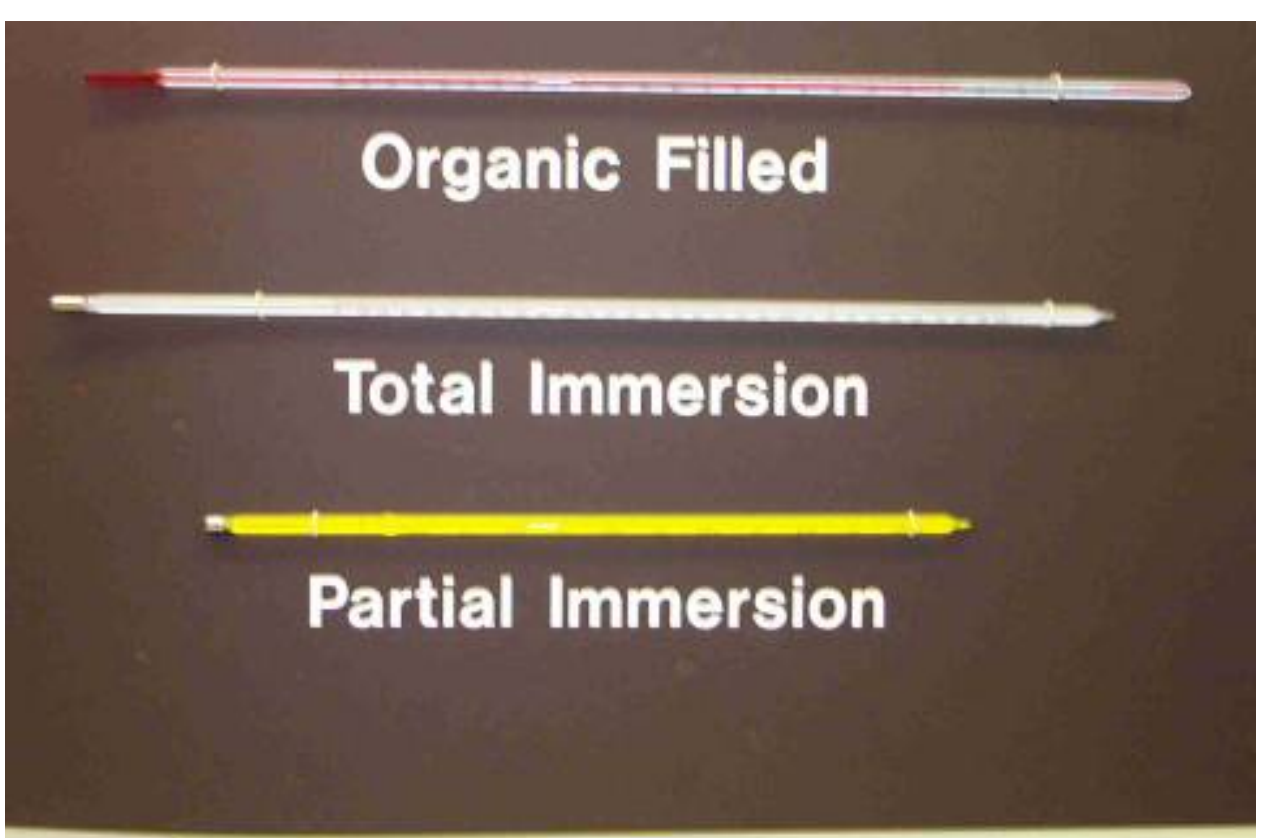




\section{Non-Mercury Liquid-in-Glass Thermometers}

- Organic liquids generally have inferior performance to mercury, but are a reasonable alternative if uncertainty requirements are modest

- Beware of drainage of organic liquid down capillary wall on cooling

- "Next-generation" organic liquids under development (Existing ASTM standard E2251); good accuracy, but check for separation of liquid column

- Greater sensitivity to stem temperature: a fundamental limitation for partial immersion thermometers - total immersion preferred

- Best results for use at steady operating temperatures, within range $-100{ }^{\circ} \mathrm{C}$ to $+100^{\circ} \mathrm{C}$; attainable expanded uncertainties of approximately $0.5^{\circ} \mathrm{C}$ to $1{ }^{\circ} \mathrm{C}$ for properly used total immersion. 


\section{Thermocouples}

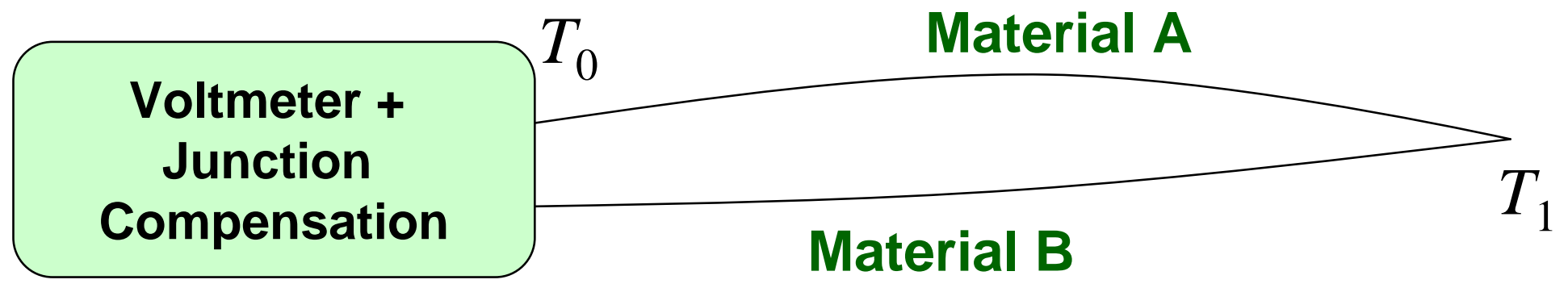

Standardized combinations of Material A vs. Material B (e.g, Type K).

When combined with typical readout uncertainty, total uncertainty is fairly large, unless care is taken with calibration.

Good for low-accuracy measurements over a broad temperature range

Type $\mathrm{K}$ is a good choice for sterilization applications; typical drift of $0.3^{\circ} \mathrm{C}$ over one year at $200^{\circ} \mathrm{C}$, for fixed installation

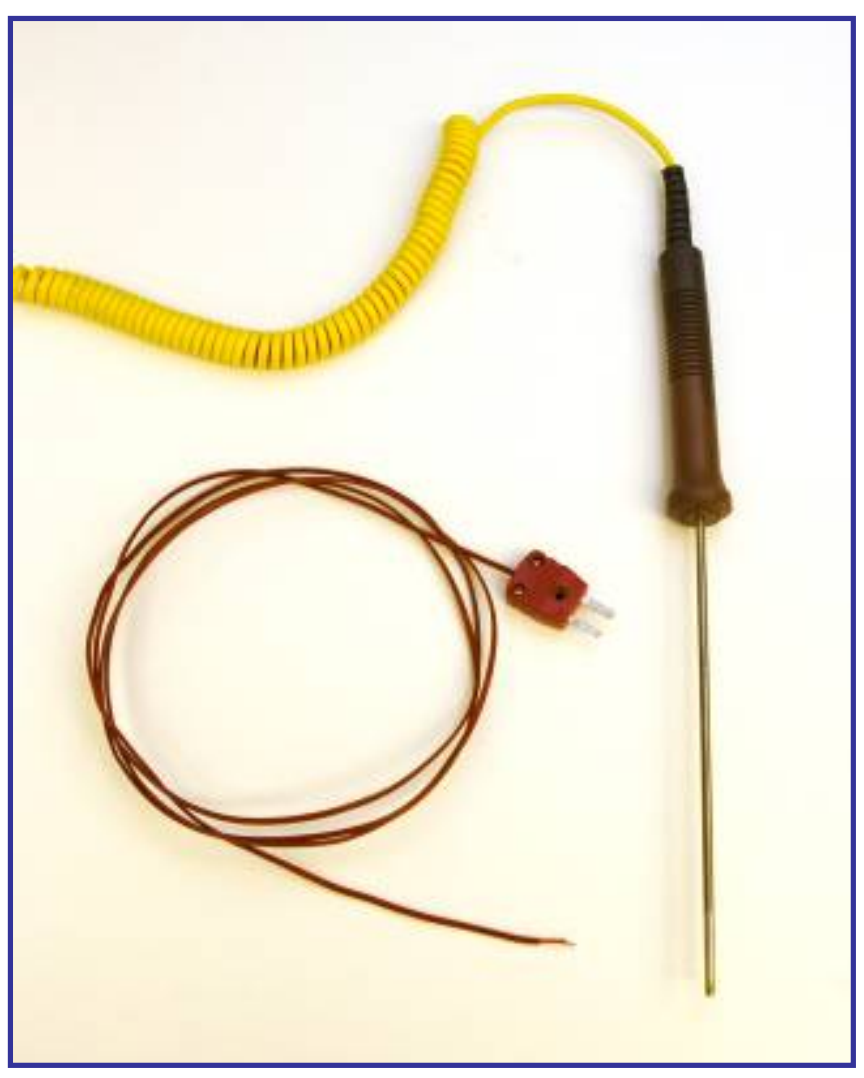




\section{Soft-Insulated Thermocouples}

Outer polymer insulation Inner polymer insulation

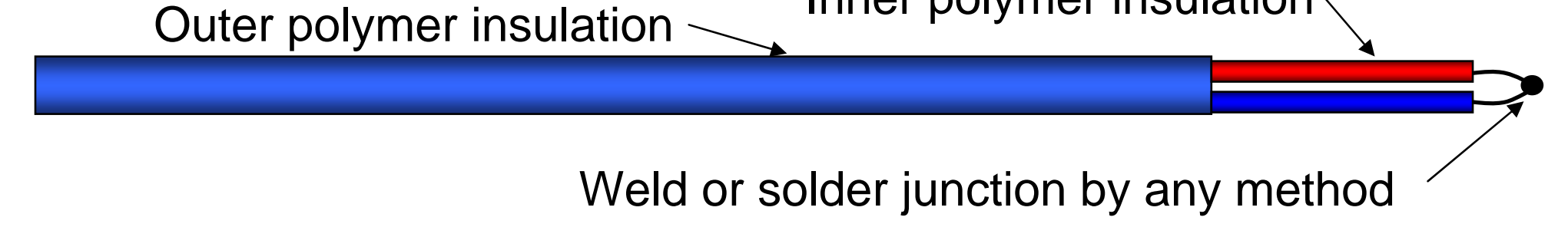

- Fluorocarbon insulations suitable to $200{ }^{\circ} \mathrm{C}\left(392^{\circ} \mathrm{F}\right)$

- Note that method for forming junction does not matter!

\section{Mineral-Insulated, Metal-Sheathed (MIMS) Thermocouples}

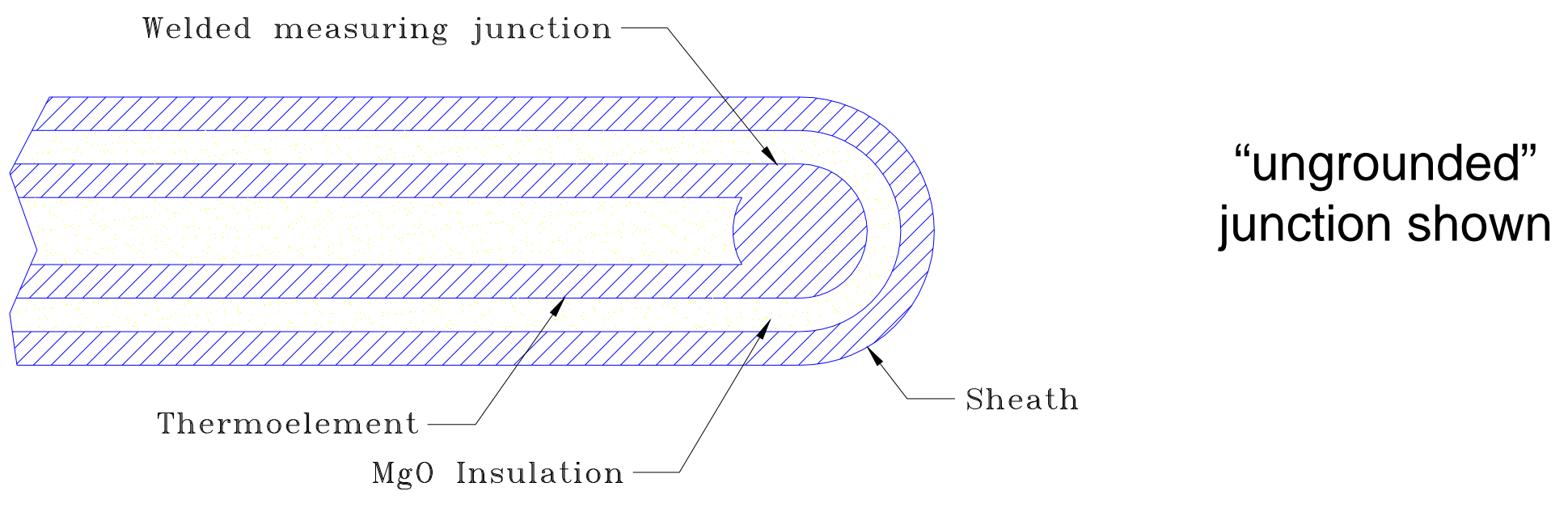

- MIMS thermocouples are available in small diameters $(0.25 \mathrm{~mm})$

- Sheath protects thermoelements from contamination \& simplifies sterilization 


\section{Effects of Pressure on Thermocouples}

Bare-wire thermocouples readily withstand high-pressure environments

Pressure distorts atomic lattice of thermoelements, resulting in small shifts in thermoelectric response.

Thermocouple measurements may be useful in understanding/validating models of adiabatic heating.

Errors are small for typical pressures $\sim 400 \mathrm{MPa}$

$$
\begin{aligned}
& \text { Error for type } \mathrm{K}=\left(-2.3 \times 10^{-6}\right)(\Delta t)(\mathrm{p} / \mathrm{MPa}) \\
& \text { Error for type } \mathrm{S}=\left(-1.9 \times 10^{-5}\right)(\Delta t)(\mathrm{p} / \mathrm{MPa})
\end{aligned}
$$

where $\Delta t=$ temperature span of thermocouple, $p=$ pressure in MPa e.g., Error for type $\mathrm{K}$ spanning $100{ }^{\circ} \mathrm{C}$ at $400 \mathrm{MPa}$ is only $-0.09{ }^{\circ} \mathrm{C}$ 


\section{Platinum Resistance Thermometers (PRTs)}

\section{Resistance element}

- Wire wound (most accurate, or for wide temperature range)

- Thick or thin film (rugged)

Resistance increases as a function of temperature

Nominal temperature range of use:

- $-200^{\circ} \mathrm{C}$ to $850^{\circ} \mathrm{C}$

Nominal resistance at $0{ }^{\circ} \mathrm{C}$

- $100 \Omega$ for wire wound

- often higher for film

PRTs are most common "Resistance Temperature Detector" (RTD)

Steel sheath containing sensor

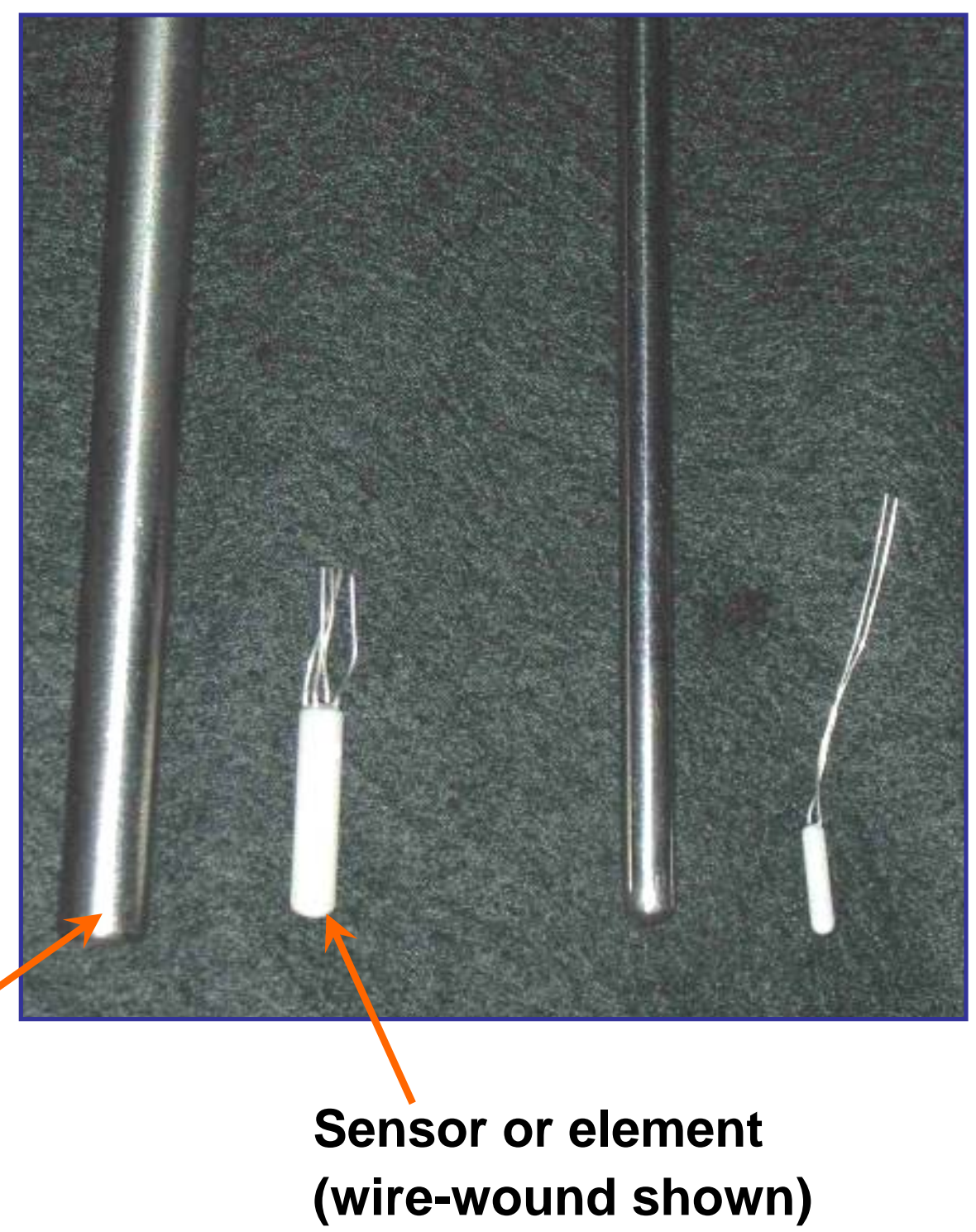


ASTM E1137 "Off the Shelf" Tolerance

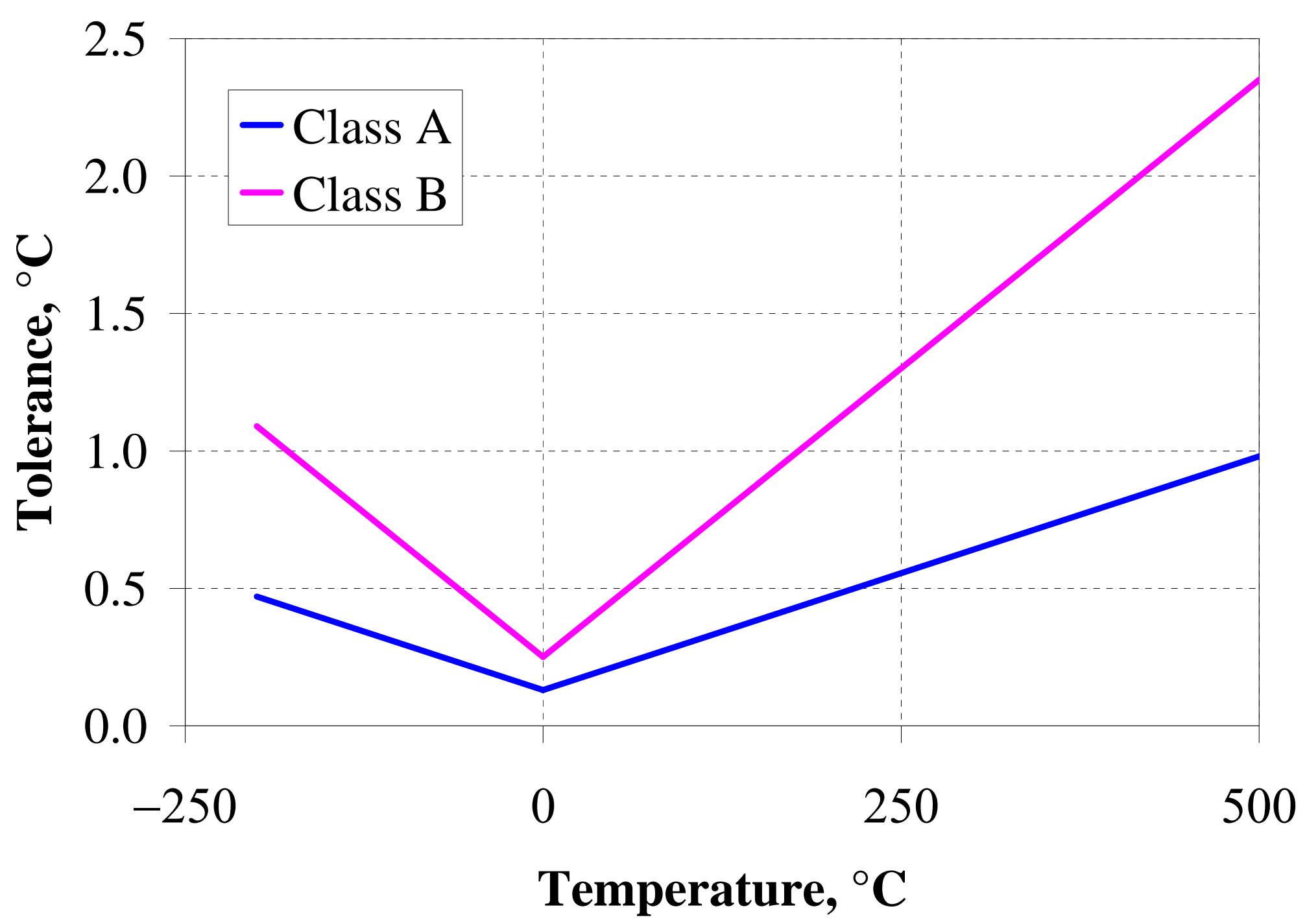

Calibrate individual units for lower uncertainty 


\section{Which Industrial PRT (IPRT) Should I Use?}

Probes vs. Bare Element: probes recommended unless element is permanently mounted. Note that moisture seal at top of probe is NOT resistant to autoclaves/steam sterilization.

Film IPRTs: good time response, small size, shock resistant; not as good as wire-wound over large $\left(>200^{\circ} \mathrm{C}\right)$ temperature spans. Drift after 365 cycles to $160{ }^{\circ} \mathrm{C} \approx 0.2^{\circ} \mathrm{C}$.

Wire-wound IPRTs with constrained coils: low accuracy, but shock resistant. Drift after 365 cycles to $160^{\circ} \mathrm{C} \approx 0.1^{\circ} \mathrm{C}$.

Wire-wound IPRTs with slightly constrained coils: best accuracy (approaching $\pm 0.01{ }^{\circ} \mathrm{C}$ over $400{ }^{\circ} \mathrm{C}$ span), sensitive to shock. Drift better than constrained coils, but highly variable among units.

Resistor configuration

- 2-wire for non-demanding applications $\left( \pm 5^{\circ} \mathrm{C}\right)$

- 3-wire for $\pm 1{ }^{\circ} \mathrm{C}$ measurements, or $\pm 5^{\circ} \mathrm{C}$ over long cables

- 4-wire for all high-accuracy measurements 


\section{Thermistors (Thermal Resistor)}

Semiconductors of ceramic material made by sintering mixtures of metallic oxides such as manganese, nickel, cobalt, copper, iron and uranium.

Temperature Range: $\quad-50{ }^{\circ} \mathrm{C}$ to $100{ }^{\circ} \mathrm{C}$

Standard Sensor Forms:

bead $300 \Omega$ to $100 \mathrm{M} \Omega$

probe bead in glass rod

NTC: $\quad$ Negative Temperature Coefficient - The vast majority of commercial thermistors used as thermometers are in the NTC category.

Commonly packaged in stainless-steel sheaths

Good choice for applications near room temperature

Use only glass-coated variety: 1-year stability $<0.01{ }^{\circ} \mathrm{C}$ up to $90{ }^{\circ} \mathrm{C}$; much higher drift at higher temperatures 


\section{What is a Digital Thermometer?}

An electronic measurement box that converts either resistance or emf of a thermometer to temperature

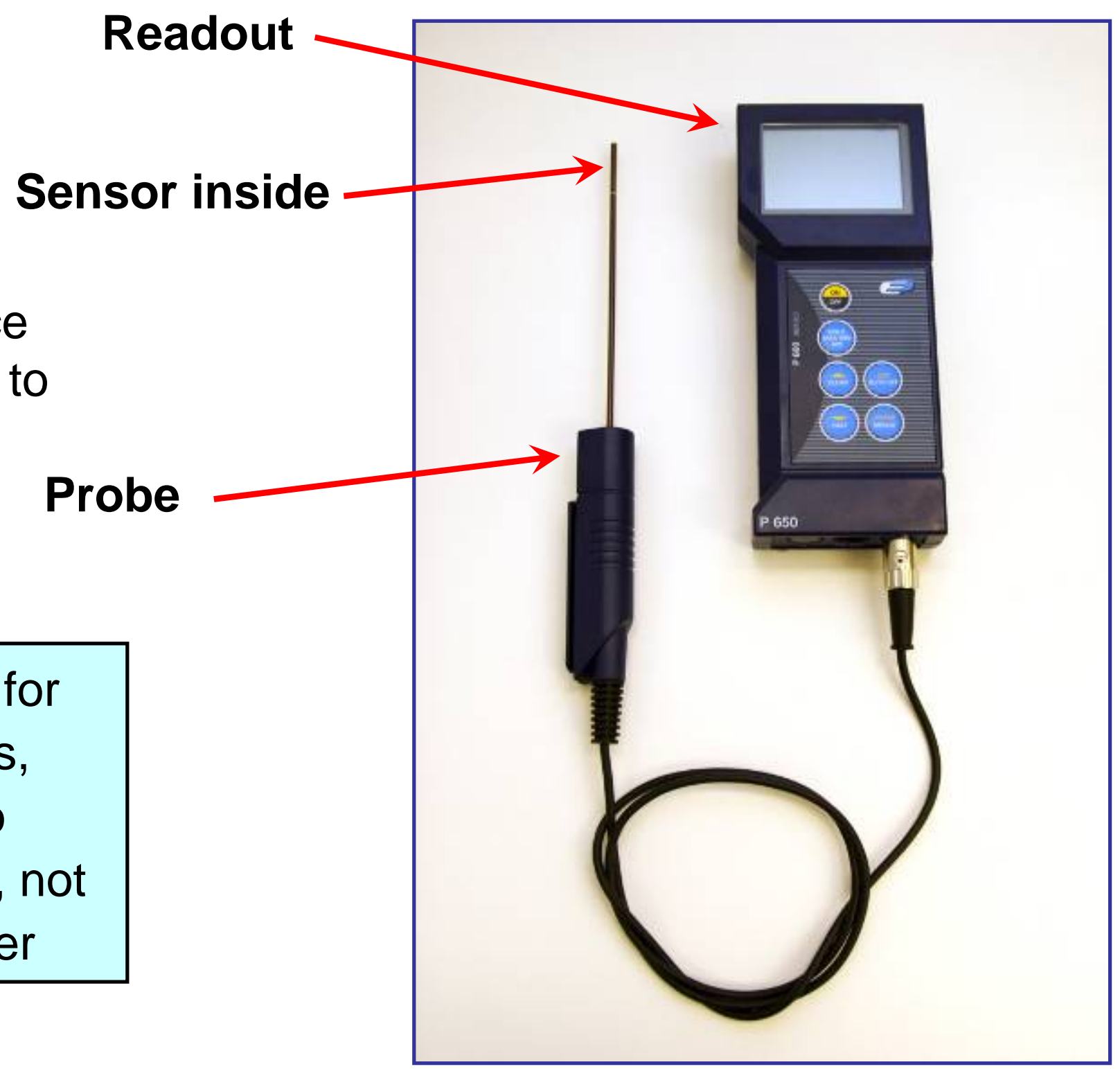

ASTM specifications for thermocouples, PRTs, thermistors pertain to sensor or probe only, not complete thermometer 


\section{Digital Thermometers}

- Device displays temperature directly by using the calibration coefficients of the thermometer

- Uncertainty: $0.001{ }^{\circ} \mathrm{C}$ to $1{ }^{\circ} \mathrm{C}$; Resolution: $0.0001^{\circ} \mathrm{C}$ to $1^{\circ} \mathrm{C}$

- Careful use requires careful reading-look at manufacturer's specifications \& know the probe type and limitations

- "Digital Thermometer" only means that you can watch the numbers on a display — no guarantee of better uncertainty

- Calibration can be as a system or as readout + separate probe

System calibration is cheaper and simpler

Probe and readout calibration allows easier repair if one element fails, allows identification of source of drift 


\section{Traceability of Temperature Measurements}

A measurement will have traceability to NIST standards if the following conditions are met:

- An unbroken chain of measurements back to NIST standards must be maintained.

- Each step of the chain must have known and documented uncertainties.

- There must be a system to ensure that the thermometers and other equipment used remain accurate between calibrations.

Common misunderstandings:

- Traceability only applies to measurements, not devices

- Traceability does not imply a particular level of uncertainty

- There is no limit to how many transfers may take place between the highest-level standards and the final thermometer, as long as the uncertainty is properly calculated. 


\section{Ensuring Good Measurements}

1. Avoid shock to the sensor and readout. With metal-sheathed thermometers, damage to the sensor will not be visually apparent.

2. For thermocouples, avoid kinks in the thermocouple wires, especially in regions where the temperature is changing from one point to another. For thermocouples used above $150{ }^{\circ} \mathrm{C}\left(30{ }^{\circ} \mathrm{F}\right)$, best uncertainties are obtained by using a separate thermocouple for each apparatus, at a fixed depth into the apparatus.

3. For resistance thermometers, calibrate and use with same lead configuration \& excitation current

4. Do not switch probes unless probes are interchangeable or coefficients are updated.

5. Be absolutely certain that the readout is set to the proper thermometer type (e.g., do not read a type $\mathrm{K}$ thermocouple with a readout set for type $\mathrm{J}$ ).

6. Do not exceed the recommended temperature limits.

7. Check the performance of the instrument regularly, following manufacturer's recommendations or past device history. 


\section{Rules of Thumb for Installation Effects}

- Probe location: understand the temperature differences between the probe location and the microbes of interest as a function of time (e.g., thermal modeling, study of wall vs. product temperature)

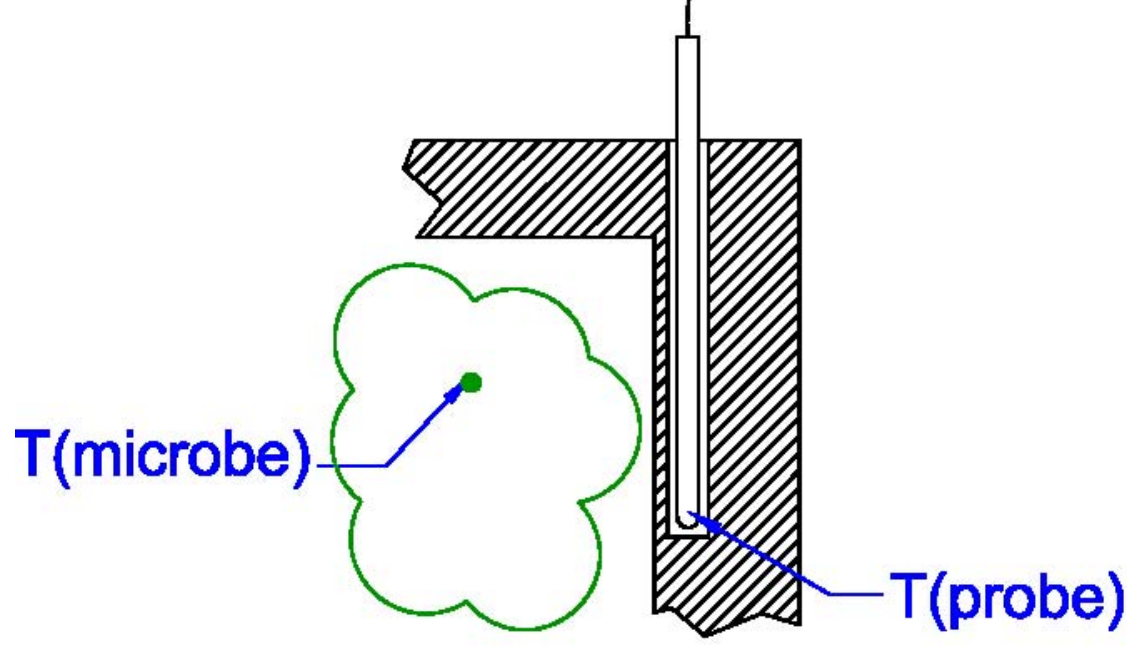

- Avoid large air gaps around probe: still air is a very poor conductor (500x worse than stainless steel)—can lead to large errors for measurement of temperature transients. Keep gaps small, or use grease.

- Design measurement geometry so at least $15 \mathrm{~cm}(6 ")$ of probe is at temperature of interest. (Use fine diameter probes if this is not possible.)

- For fluids, physical state \& conditions of flow are critical:

Still gas (e.g., gas convection suppressed in insulation)

Flowing gas (e.g., convection oven)

Condensing vapor (e.g., steam in an autoclave) 


\section{Thermometer Verification Methods}

1. Periodically have the thermometer recalibrated.

If recalibration indicates that thermometer drift exceeds an allowable tolerance:

- Improve handling of the thermometer

- Choose thermometer with better stability, or

- Shorten interval between calibrations.

2. Check the readings of the thermometer at the ice $\left(0^{\circ} \mathrm{C}, 32^{\circ} \mathrm{F}\right)$ and/or steam point (near $\left.100{ }^{\circ} \mathrm{C}, 212^{\circ} \mathrm{F}\right)$.

The NIST Thermometry Group can provide simple procedures for preparing an ice or steam point.

3. Compare the reading of a thermometer to another, recently calibrated thermometer.

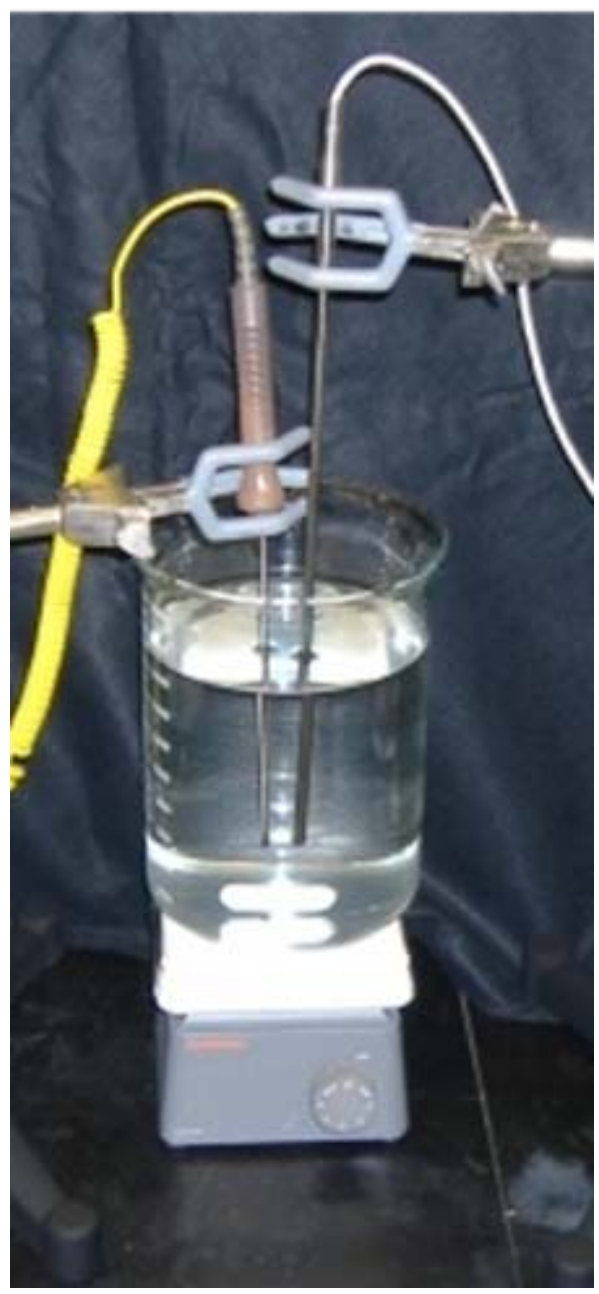

room-temperature comparison 


\section{Electromagnetic Interference}

Not a major issue for laboratory-scale experiments with welldesigned electronics

\section{Design:}

- Noise rejection can be hard to glean from manufacturer's readout specifications; specifications for digital multimeters are better.

- Avoid long cable runs

- Use twisted pair for shielding against $60 \mathrm{~Hz}$ noise

- If radio-frequency interference causes problems, add an outer grounded shield

- Use probes with sensor isolated ("ungrounded") from probe wall

\section{Diagnosis:}

- While continuously monitoring temperature, shut off sources of electrical noise. If EMI is a problem, temperature will show a step change (actual temperature change will show a change in slope). 


\section{Learning More}

Good general guides:

Traceable Temperatures by J. Nicholas and D. R. White (Wiley, 2001)

Handbook of Temperature Measurement (Vols 1-3), ed. Robin E. Bentley (Springer, 1998).

Additional reference for thermocouples:

ASTM Manual on the Use of Thermocouples in Temperature Measurement, MNL-12 (ASTM, West Conshohocken, PA, 1993).

Modern uncertainty analysis:

http://physics.nist.gov/cuu/Uncertainty/index.html

Methods to set calibration intervals, see:

"Guidelines for the determination of calibration intervals of measuring instruments," ILAC-G24, (International Laboratory Accreditation Cooperation, 2007). 